\title{
Oxide and chalcogenide nanoparticles from hydrothermal/solvothermal reactions
}

\author{
Michael Rajamathi ${ }^{\mathrm{a}}$, Ram Seshadri ${ }^{\mathrm{b}, *}$ \\ ${ }^{a}$ Department of Chemistry, St. Joseph's College, Bangalore 560 027, India \\ ${ }^{\mathrm{b}}$ Solid State and Structural Chemistry Unit, Indian Institute of Science, Bangalore 560 012, India
}

\begin{abstract}
We review recent reports of solvothermal or hydrothermal procedures for the preparation of isolated nanoparticles of some important oxide and chalcogenide materials. The synthetic procedures listed here have the advantages of being relatively inexpensive in terms of the solvents used, arguably green (when water is the solvent) and amenable to scale-up. Handling or processing under inert conditions are rarely called for. We include descriptions of work involving the preparation of capped quantum dots using solvothermal techniques as well as microwave-hydrothermal routes and flow-hydrothermal routes that allow continuous and rapid processing of nanoparticulate materials. (C) 2002 Elsevier Science Ltd. All rights reserved.
\end{abstract}

\section{Introduction}

As the science of nanoparticles matures, there is inevitably great emphasis being placed on scaling up procedures for their syntheses. Most procedures for the preparation of oxide and chalcogenide nanoparticles are solution-based, and often involve reactions carried out near the boiling point of the solvent. In order to obtain crystalline, monodisperse nanoparticles, it is usually necessary to work at relatively high temperatures. This is where a solvent such as trioctyl phosphine oxide (TOPO) is useful for the preparation of semiconductor quantum dots [1], certain transition metal oxide nanoparticles [2] and metal nanoparticles [3]. In these examples, TOPO acts both as solvent and capping agent. In a similar vein, Alivisatos and coworkers [4] have used trioctylamine to thermolyse metal complexes so as to obtain the corresponding oxide nanoparticles.

The problem with these high-temperature solvents, apart from their toxicity, is that they can be very expensive, which makes scale-up non-viable. Handling them (for example, attempting to distill/evaporate/purify) is also not always easy. On the other hand, more common, inexpensive laboratory solvents also cause problems due to the limitations caused by their rather low boiling points. However, a simple method to circumvent this problem lies

*Corresponding author. Fax: +91-80-360-1310.

E-mail address: seshadri@sscu.iisc.ernet.in (R. Seshadri). in using a solvent well-above its boiling point, i.e. the solvent is heated in a sealed vessel (autoclave, bomb, etc.), so that the autogenous pressure far exceeds the ambient pressure. This automatically raises the effective boiling point of the solvent. Such a technique (which we refer to henceforth as solvothermal) is indeed extensively used in the preparation of inorganic solids, and in particular of zeolite materials [5]. In the special case of the solvent being water, the technique is often called hydrothermal. In our working definition, we do not require the system to be supercritical and indeed, in most solvothermal syntheses, the temperature employed is well below the critical temperature.

In this review, we limit ourselves to the uses of hydro/ solvothermal techniques for the preparation of nanoparticles of oxides and chalcogenides. For the most part, our interest is in unsupported nanoparticles and we have attempted to focus on procedures that: (i) either involve capping by surfactant, or at least, suggest the possibility for doing so; and/or (ii) result in sub-10 nm particles. We do not discuss the extensive literature on the hydrothermal sol-gel processing of nanophase ceramic materials [6]. To use this review, we suggest that the reader turns to Table 1 and selects either the material of choice, or the solvothermal conditions and then proceeds to find the section under the different subheadings. We have attempted to order the table in the same manner that the material is presented in the text so that relating table contents with text is made easier. 
Table 1

\begin{tabular}{|c|c|c|c|c|}
\hline Compound & Size $(\mathrm{nm})$ & Starting materials & Solvent & Reference \\
\hline \multicolumn{5}{|l|}{ Oxides } \\
\hline $\mathrm{CeO}_{2}$ & 2 & $\mathrm{Ce}$ & 2-Methoxyethanol & [*9] \\
\hline $\mathrm{ZnGa}_{2} \mathrm{O}_{4}$ & 10 & $\mathrm{Zn}, \mathrm{GaCl}_{3}$ & $\mathrm{H}_{2} \mathrm{O}$ & {$[10]$} \\
\hline $\mathrm{TiO}_{2}$ & Sub-100 & $\mathrm{Ti}(\mathrm{OR})_{4}$ & $\mathrm{H}_{2} \mathrm{O}$ & {$[* * 11]$} \\
\hline $\mathrm{TiO}_{2}$ & & $\mathrm{TiCl}_{4}$ & $\mathrm{H}_{2} \mathrm{O}$ & {$[12]$} \\
\hline $\mathrm{TiO}_{2}$ & 4 & $\mathrm{TiCl}_{4}$ & $\mathrm{H}_{2} \mathrm{O}$ & {$[13]$} \\
\hline $\mathrm{ZrO}_{2}$ & $3-5$ & $\mathrm{Zr}(\mathrm{OR})_{4}$ & Ethanol & {$[14]$} \\
\hline $\mathrm{ZnGa}_{2} \mathrm{O}_{4}$ & $5-25$ & $\mathrm{ZnSO}_{4}, \mathrm{GaSO}_{4}$ & $\mathrm{H}_{2} \mathrm{O}$ & {$[15]$} \\
\hline $\mathrm{TiO}_{2}$ & 50 & $\mathrm{Ti}(\mathrm{OR})_{4}$ & $\mathrm{H}_{2} \mathrm{O}$, cyclohexane & {$[16]$} \\
\hline$\gamma-\mathrm{Fe}_{2} \mathrm{O}_{3}, \mathrm{CoFe}_{2} \mathrm{O}_{4}$ & $7-12,7$ & Co, $\mathrm{Fe}$ cupferron complexes & Toluene & {$[* 17]$} \\
\hline \multicolumn{5}{|l|}{ Chalcogenides } \\
\hline $\mathrm{ZnSe}$ & $12-16$ & $\mathrm{Zn}, \mathrm{Se}$ & Pyridine & {$[21]$} \\
\hline $\mathrm{ZnSe}, \mathrm{CdSe}$ & $70-100$ & $\mathrm{Zn} / \mathrm{Cd}, \mathrm{Se}$ & $\mathrm{H}_{2} \mathrm{O}$ & {$[* 22]$} \\
\hline $\mathrm{ZnSe}$ & 18 & $\mathrm{Zn}, \mathrm{Se}$ & Ethylenediamine & {$[23]$} \\
\hline $\mathrm{CdS}$ & 6 & $\mathrm{Cd}$ nitrate or sulphate, thiourea & Ethylene glycol & {$[24]$} \\
\hline $\mathrm{CdSe}$ & 3 & Cd stearate, $\mathrm{Se}$ & Toluene & {$[* 25]$} \\
\hline $\mathrm{Cu}_{2-\mathrm{x}} \mathrm{Se}$ & 18 & $\mathrm{CuI}, \mathrm{Se}$ & Ethylenediamine & [27] \\
\hline $\mathrm{Co}_{9} \mathrm{~S}_{8}$ & 6 & $\mathrm{Co}\left(\mathrm{CH}_{3} \mathrm{COO}\right)_{2}$, thiourea, hydrazine & $\mathrm{H}_{2} \mathrm{O}$ & {$[28]$} \\
\hline $\mathrm{SnSe}$ & 45 & $\mathrm{SnCl}_{2}, \mathrm{Se}, \mathrm{Na}$ & Ethylenediamine & [29] \\
\hline $\mathrm{Bi}_{2} \mathrm{Se}_{3}$ & 25 & $\mathrm{BiCl}_{3}, \mathrm{Se}, \mathrm{NaI}$ & Ethylenediamine & {$[30]$} \\
\hline $\mathrm{In}_{2} \mathrm{~S}_{3}$ & 15 & $\mathrm{InCl}_{3}, \mathrm{Na}_{2} \mathrm{~S}_{2} \mathrm{O}_{3}(\mathrm{CTAB})$ & Ethanol & [31] \\
\hline $\mathrm{MSe}_{2}(\mathrm{M}=\mathrm{Ni}, \mathrm{Co}, \mathrm{Fe})$ & & $\mathrm{MCl}_{2}$, hydrazine, Se & $\mathrm{H}_{2} \mathrm{O}$ or $\mathrm{DMF}$ & {$[32]$} \\
\hline $\mathrm{ME}_{2}(\mathrm{M}=\mathrm{Ni}, \mathrm{Co}, \mathrm{Fe}, \mathrm{Mo})$ & & $\mathrm{MCl}_{2}, \mathrm{Na}_{2} \mathrm{ESO}_{3}(\mathrm{E}=\mathrm{S}, \mathrm{Se})$ & $\mathrm{H}_{2} \mathrm{O}$ & {$[* 33]$} \\
\hline $\mathrm{CuInSe}_{2}$ & 15 & $\mathrm{CuCl}_{2}, \mathrm{InCl}_{3}, \mathrm{Se}$ & Diethylamine & {$[34]$} \\
\hline $\mathrm{CuIn}(\mathrm{S}, \mathrm{Se})_{2}$ & 15 & $\mathrm{CuCl}_{2}, \mathrm{InCl}_{3}, \mathrm{~S}, \mathrm{Se}$ & Ethylenediamine & [35] \\
\hline $\mathrm{AgMS}_{2}(\mathrm{M}=\mathrm{In}, \mathrm{Ga})$ & 6,10 & $\mathrm{AgCl}, \mathrm{M}, \mathrm{S}$ & Ethylenediamine & {$[36]$} \\
\hline $\mathrm{CuMS}_{2}(\mathrm{M}=\mathrm{In}, \mathrm{Ga})$ & 10,35 & $\mathrm{CuCl}, \mathrm{M}, \mathrm{S}$ & $\mathrm{H}_{2} \mathrm{O}$ & [37] \\
\hline Mn-doped ZnS & 12 & $\mathrm{MCl}_{2}, \mathrm{Na}_{2} \mathrm{~S}$ & $\mathrm{H}_{2} \mathrm{O}$, pet. ether & {$[38]$} \\
\hline
\end{tabular}

\section{Autogenous pressures in solvothermal reactions}

It is useful to be able to estimate the pressures generated within a solvothermal reaction bomb-if only for reasons of safety. Cubic equations of state [7] turn out to be appropriate for this purpose. For a given temperature $T$ and pressure $p$, they yield three volume roots. The smallest real root corresponds to the molar volume $V_{\mathrm{m}}$ of the liquid fraction in the bomb. Plots of isobars (constant pressure) of the molar volume as a function of temperature can be calculated from these equations. The starting molar volume of the liquid is calculated using the formula weight of the liquid, the filling fraction in the bomb and the volume of the bomb. This molar volume is then interpolated into the plot in order to obtain an estimate of the kinds of pressure being developed in the bomb. We have used the PengRobinson equation of state for the purpose. This equation takes the form [8]:

$p=\left[R T /\left(V_{\mathrm{m}}-b\right)\right]-\left[a /\left(V_{\mathrm{m}}^{2}+2 b V_{\mathrm{m}}-b^{2}\right)\right]$

The parameters $a$ and $b$ are given by:

$a=0.45724 R^{2} T_{\mathrm{C}}^{2}\left[1+f_{\omega}\left(1-T_{\mathrm{r}}^{1 / 2}\right)\right]^{2} / p_{\mathrm{C}}$

$b=0.07780 R T_{\mathrm{C}} / P_{\mathrm{C}}$ where $f_{\omega}=0.37464+1.54226 \omega-0.26992 \omega^{2}$.

The subscript ' $r$ ' refers to reduced conditions (for example, $T_{\mathrm{r}}=T / T_{\mathrm{C}}$ ) and the subscript ' $\mathrm{C}$ ' denotes the critical value. $T_{\mathrm{C}}, p_{\mathrm{C}}$ and the acentric factor $\omega$ are tabulated for many different solvents, for example in the textbook of Reid et al. [8]. Fig. 1 displays the isobars of the molar volume of toluene at different temperatures calculated using the above procedure. We interpret the plot as follows: For a filling fraction of 0.7 of toluene in the bomb, we obtain a molar volume of approximately 0.151 $\mathrm{mol}^{-1}$. This means, at $250^{\circ} \mathrm{C}$, the pressure within the bomb is approximately $100 \mathrm{bar}$. At lower temperatures, or smaller filling fractions, the pressure is less.

\section{Oxide nanoparticles}

As mentioned previously, we focus on solvothermal (including hydrothermal) routes to the preparation of unsupported oxide nanoparticles. We do not review the rather extensive literature on the hydrothermal sol-gel processing.

\subsection{Routes involving oxidation}

Metal powders are easily oxidized under solvothermal 


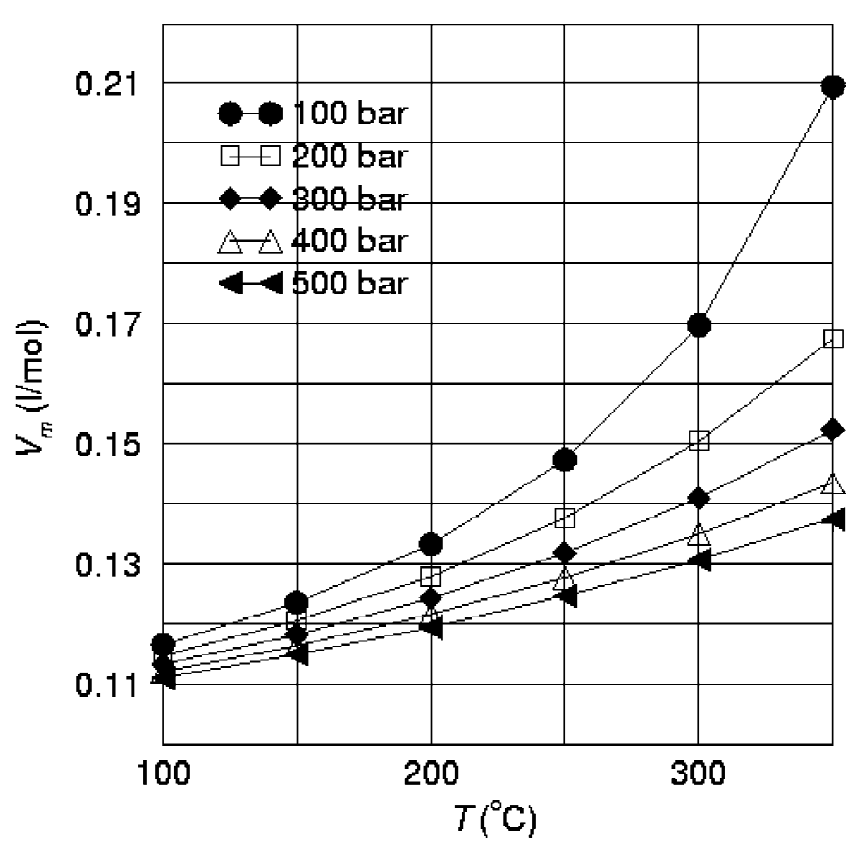

Fig. 1. Isobars displaying the dependence of the starting molar volume of toluene taken in a closed bomb, on the temperature. The isobars were obtained using the Peng-Robinson equation of state as explained in the text.

conditions to the corresponding oxides. An example of this is the preparation of $\mathrm{CeO}_{2}$ particles in the 2-nm size range by reaction of Ce metal with 2-methoxy ethanol (previously purged with $\mathrm{N}_{2}$ to remove dissolved oxygen) [*9]. The conditions were: $T=200-250{ }^{\circ} \mathrm{C}, t=2 \mathrm{~h}$. Under these conditions, the authors obtained mostly a yellow solid that was $\mathrm{CeO}_{2}$ with large particle sizes $(\sim 100 \mathrm{~nm})$. In addition, they obtained a brown solution containing the $2-\mathrm{nm} \mathrm{CeO}_{2}$ particles. These could be salted out of the solution using $\mathrm{NaCl}$. Interestingly, the particles could be redispersed in water to give clear solutions that exhibit Beer-Lambert concentration dependence in optical absorption spectra. The authors suggest that these are the smallest ceria particles reported so far.

A combination of oxidation and hydrolysis under hydrothermal conditions has been used to prepare 10-nm spinel $\mathrm{ZnGa}_{2} \mathrm{O}_{4}$ particles [10]. The starting materials were $\mathrm{Zn}$ powder (in $10-20 \%$ excess) and $\mathrm{GaCl}_{3}$. The conditions were: $T=150{ }^{\circ} \mathrm{C} ; t=10 \mathrm{~h}$. The authors suggest that dissolution of $\mathrm{Zn}$ raises the $\mathrm{pH}$ thereby assisting in the hydrolysis of $\mathrm{Ga}^{\mathrm{III}}$. The temperature, initial $\mathrm{pH}$ of the $\mathrm{GaCl}_{3}$ solution and the $\mathrm{Zn} / \mathrm{Ga}$ ratio affected the yield, purity and particle size of the product. At temperatures less than $130{ }^{\circ} \mathrm{C}$, the reaction was incomplete. At temperatures greater than $180^{\circ} \mathrm{C}$, the particle sizes were large. When the starting $\mathrm{pH}$ of $\mathrm{GaCl}_{3}$ was 3 or more, $\mathrm{Ga}_{2} \mathrm{O}_{3}$ formed as an impurity. When the $\mathrm{Zn} / \mathrm{Ga}$ ratio was $1: 2$, the reaction was incomplete; an excess of $\mathrm{Zn}$ was found to be important. Excess $\mathrm{ZnCl}_{2}$ formed could be washed away from the final product.

\subsection{Routes involving hydrolysis}

Hydrolytic routes are popular for the preparation of oxide nanoparticles. In aqueous solutions, a trivalent ion such as $\mathrm{Fe}^{\mathrm{III}}$ is expected to be solvated by a shell of water molecules. One might therefore write the hydrolysis as:

$2 \mathrm{M}^{3+}\left(\mathrm{H}_{2} \mathrm{O}\right)_{6} \rightarrow \mathrm{M}_{2} \mathrm{O}_{3} \downarrow+9 \mathrm{H}_{2} \mathrm{O}+6 \mathrm{H}^{+}$

This scheme indicates the necessity to raise the $\mathrm{pH}$ in the hydrolytic reaction, in order to remove protons that are generated and thereby to drive the reaction to the right. A popular hydrolytic route to oxides is the (acid or basecatalyzed) polycondensation of alkoxy compounds. This is particularly useful for compounds with quadrivalent ions, such as $\mathrm{Si}^{\mathrm{IV}}, \mathrm{Ti}^{\mathrm{IV}}, \mathrm{Zr}^{\mathrm{IV}}$, etc. For example, starting with titanium tetra-isopropoxide $\operatorname{Ti}(\mathrm{OR})_{4}$, one can write the acid or base-catalyzed hydrolysis as:

$\mathrm{Ti}(\mathrm{OR})_{4}+2 \mathrm{H}_{2} \mathrm{O} \rightarrow \mathrm{TiO}_{2}+4 \mathrm{ROH}$

In detailed and very elegant work, Chemseddine and Moritz [**11] have described the preparation of sub-100 $\mathrm{nm}$ anatase nanoparticles of different sizes and also shapes. Their procedure involves a combination of hydrolysis and polycondensation of $\mathrm{Ti}(\mathrm{OR})_{4}$ in the presence of tetramethyl ammonium hydroxide, with a preliminary heat treatment under reflux, and final heat treatments $(T=175-$ $200{ }^{\circ} \mathrm{C}, t=5 \mathrm{~h}$ ) being carried out in a Ti autoclave. The monodispersity of the anatase nanoparticles was sufficiently high that the authors were able to form nanocrystal superlattices and have presented not only TEM images in support of the formation of such superlattices, but also, low-angle powder X-ray diffraction data showing superlattice reflections.

Yanqing et al. [12] have hydrolyzed aqueous solutions of $\mathrm{TiCl}_{4}$ hydrothermally $\left(T=100-300{ }^{\circ} \mathrm{C}\right.$ for different durations varying from 6 to $44 \mathrm{~h}$ ). The size, morphology and phase of the resultant $\mathrm{TiO}_{2}$ particles could be controlled. The amount of rutile increased with time, temperature and the initial $\mathrm{TiCl}_{4}$ concentration. Small particle sizes were found when the initial $\mathrm{TiCl}_{4}$ concentration was low and the reaction times were kept short.

$\mathrm{TiO}_{2}$ (anatase and rutile) nanoparticles have been prepared starting from stabilized $\mathrm{TiCl}_{4}$ solutions by Yin et al. [13] The procedure for the anatase nanoparticles involved hydrothermal treatment $\left(T=220^{\circ} \mathrm{C}, t=2\right.$ and $\left.4 \mathrm{~h}\right)$ in the presence of citric acid. After $2 \mathrm{~h}, 4-\mathrm{nm}$ particles were formed and after $4 \mathrm{~h}, 6-\mathrm{nm}$ particles were formed. When a similar procedure was carried out but in the absence of citric acid, fibrous rutile was obtained. The particles obtained were smaller and more monodisperse than those which could be obtained through sol-gel processing. This is because the reaction, according to the authors, involves polycondensation of the anionic species $\left[\mathrm{Ti}(\mathrm{OH})_{x}(\text { citrate })_{y} \mathrm{Cl}_{z}\right]^{n-}$.

Sun and coworkers [14] have prepared 3-5 $\mathrm{nm} \mathrm{ZrO}_{2}$ 
nanoparticles starting with $\mathrm{Zr}(\mathrm{OR})_{4}(\mathrm{R}=n$-propyl), ethanol, diethylene glycol and water. In different experiments, ammonia and $\mathrm{HCl}$ were also used. The solvothermal treatment conditions were $T=190-230{ }^{\circ} \mathrm{C}, t=24 \mathrm{~h}$. In the absence of glycol, the tetragonal phase is obtained. When glycol is used, cubic $\mathrm{ZrO}_{2}$ nanoparticles could be obtained. Optimal starting ratios were 85:1 for ethanol/Zr; 20:1 for diethyleneglycol/Zr and 0.002 for $\mathrm{HCl} / \mathrm{Zr}$. Under these conditions, well-separated, small particles were obtained. The mechanism proposed is that the glycol coordinates with the $\mathrm{Zr}$ ion and the polycondensation of this species is sterically hindered so that the particle growth is limited.

Hirano [15] has described the preparation of spinel $\mathrm{ZnGa}_{2} \mathrm{O}_{4}$ nanoparticles starting with $\mathrm{Zn}$ and $\mathrm{Ga}$ sulphates with $\mathrm{NH}_{3}$ added to adjust the $\mathrm{pH}$ to different values (initial $\mathrm{pH}$ varied from 2.5 through 10 ). The reactants were then treated hydrothermally at $T=150-240{ }^{\circ} \mathrm{C}, t=5-50 \mathrm{~h}$. An approximately $50 \%$ excess $\mathrm{Zn}^{\mathrm{II}}$ was found to be necessary. Particle size increased with starting $\mathrm{pH}$, and based on different parameters including $T$, could be varied from 5 to $25 \mathrm{~nm}$.

Wu et al. [16] have demonstrated that microemulsion techniques of material containment can be combined with solvothermal routes to prepare rutile and anatase $\mathrm{TiO}_{2}$ nanoparticles. These authors took a water-in-oil (cyclohexane) microemulsion using Triton X-100 and $n$-hexanol as emulsifiers. The aqueous phase had dilute $\mathrm{HCl}$ or dilute $\mathrm{HNO}_{3}$, with $\mathrm{Ti}(\mathrm{OR})_{4}(\mathrm{R}=n$-butyl $)$ as the reactant. The treatment conditions used were $T=120-200{ }^{\circ} \mathrm{C}, t=12$ $144 \mathrm{~h}$. The product phase and morphology could be controlled by the starting $\mathrm{HCl}$ or $\mathrm{HNO}_{3}$ concentrations. When the $\mathrm{HCl}$ concentrations were high, rutile nanorods were produced. When $0.5 \mathrm{M} \mathrm{HNO}_{3}$ was used, anatase nanoparticles were obtained. Typical anatase particle sizes were $50 \mathrm{~nm}$. High reaction times and temperatures favor rutile formation. These authors have recorded TEM images of the microemulsions before hydrothermal treatment and see that the emulsions have the shapes of the products they form on heat-treatment.

\subsection{Route involving thermolysis}

In our laboratory, we have prepared a number of transition metal oxide nanoparticles containing either a single metal atom or two metal atoms (spinel oxides) using a thermolytic route involving the decomposition of cupferron complexes of transition metal ions in solvothermal toluene [*17]. This route is an extension of the one presented by Rockenberger et al. [4], who have used trioctyl amine as the solvent for the decomposition of cupferron complexes. Cupferron is $\mathrm{N}$-phenyl, $\mathrm{N}$-nitroso hydroxylamine. A typical cupferron complex of a divalent metal ion $\mathrm{M}^{2+}$ is shown in Fig. 2. The crystal structure displayed is that of $\mathrm{Cu}$ (cupferron) ${ }_{2}$ with the coordinates taken from Ref. [18]. The complex is bonded to the metal atom through $\mathrm{O}$ and heating results in the decomposition

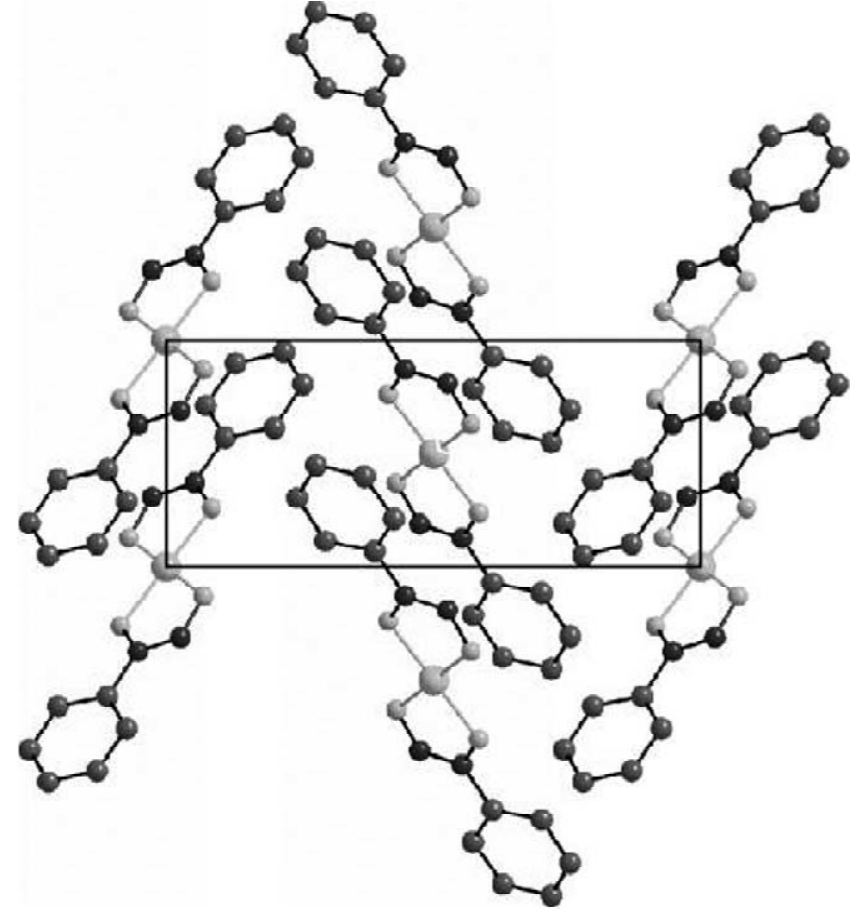

Fig. 2. Crystal structure of a typical cupferron complex. This one is of $\mathrm{Cu}$ (cupferron) $)_{2}$, with the large grey spheres representing the metal, and the organic ligand chelating to the metal through the small grey spheres which are oxygen. Such complexes are precursors for the thermolytic preparation of a large number of oxide nanoparticles.

of the complex to metal oxide with volatile by-products such as nitrosobenzene being produced.

In [*17], we have shown that magnetic sub-10 nm $\gamma-\mathrm{Fe}_{2} \mathrm{O}_{3}$ nanoparticles as well as magnetic spinel nanoparticles such as $\mathrm{CoFe}_{2} \mathrm{O}_{4}$ can be prepared by starting with the corresponding cupferron complexes and heating them solvothermally in toluene in the presence of an amine (n-octylamine or $n$-dodecylamine) capping agent. The nanoparticles so produced are superparamagnetic. Dispersity can be controlled so that as-prepared nanoparticles show particle size distributions with widths of about $20 \%$. To our knowledge, this is the only example of capped oxide nanoparticles being produced using a solvothermal technique. Fig. 3 displays the TEM image of octylaminecapped 7-nm $\mathrm{CoFe}_{2} \mathrm{O}_{4}$ spinel nanoparticles. This is only one of many mixed transition metal oxides that can be made using this route.

\section{Chalcogenide nanoparticles}

An important landmark preparation, actually of a pnictide InAs [19], has led the way to the preparation of a number of different chalcogenide nanoparticles using solvothermal routes. Much of the work comes from the group of Yi-Tai Qian in Hefei, China, and has been reviewed previously [**20]. In the InAs preparation [19], 

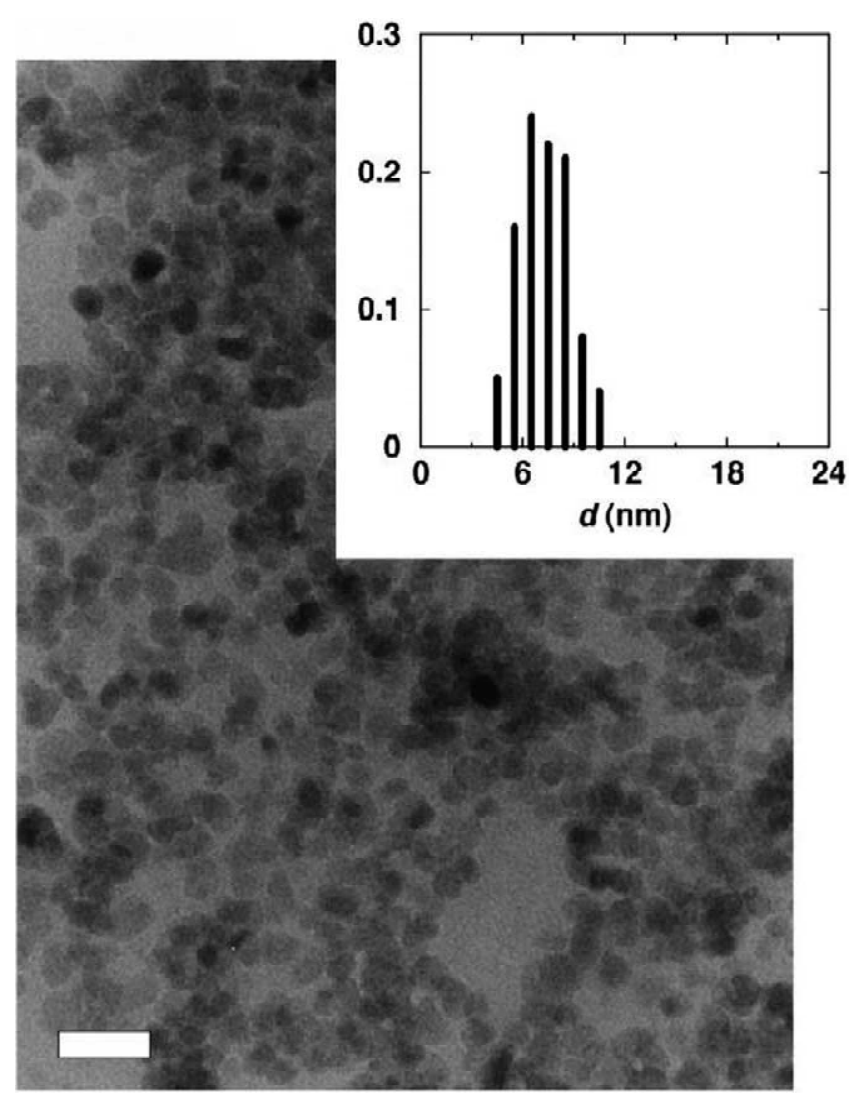

Fig. 3. TEM image of 7-nm $n$-octylamine-capped $\mathrm{CoFe}_{2} \mathrm{O}_{4}$ nanoparticles prepared by the solvothermal decomposition of cupferron complexes in toluene. The bar is $20 \mathrm{~nm}$. Reproduced with permission from The Royal Society of Chemistry [*17].

the authors took $\mathrm{InCl}_{3}, \mathrm{AsCl}_{3}$ and $\mathrm{Zn}$ powder in xylene, and treated the reactants solvothermally at $T=150{ }^{\circ} \mathrm{C}$, $t=48 \mathrm{~h}$. The product was $15-\mathrm{nm}$ InAs nanoparticles. The reaction takes place between the freshly formed elements that are obtained on the reduction of the In and As halides by $\mathrm{Zn}$. Generally, water would be avoided in such a reaction. Here, trace quantities are actually beneficial for product formation. The suggested reaction is

$$
\begin{aligned}
& 3 \mathrm{Zn}+6 \mathrm{H}_{2} \mathrm{O} \rightarrow 3 \mathrm{Zn}(\mathrm{OH})_{2}+6 \mathrm{H} \\
& \mathrm{InCl}_{3}+\mathrm{AsCl}_{3}+6 \mathrm{H} \rightarrow \mathrm{InAs}+6 \mathrm{HCl} \\
& 3 \mathrm{Zn}(\mathrm{OH})_{3}+6 \mathrm{HCl} \rightarrow 3 \mathrm{ZnCl}_{2}+6 \mathrm{H}_{2} \mathrm{O}
\end{aligned}
$$

\subsection{Reactions starting from the elements}

ZnSe nanoparticles $(12-16 \mathrm{~nm})$ have been prepared [21] by reacting the elements in pyridine $\left(T=180^{\circ} \mathrm{C}, t=8 \mathrm{~h}\right)$. The TEM images show platelets of aggregated particles, along with individual spherical particles. The cubic zinc blende structure was obtained under these conditions. The reaction could not be carried out in benzene; and in ethylenediamine, a complex was obtained. A similar reaction with $\mathrm{Zn}$ and $\mathrm{S}$ gives different particles sizes depending on the time of heat treatment: $3 \mathrm{~nm}(t=5 \mathrm{~h}), 10$ $\mathrm{nm}(t=10 \mathrm{~h}) 18 \mathrm{~nm}(t=24 \mathrm{~h})$. The particles were spherical. In reactions such as these, it is possible that the amine solvent solvates electrons that are given up by the metal. These electrons reduce the chalcogen to the anion resulting in precipitation.

$\mathrm{ZnSe}$ and CdSe particles $(70-100 \mathrm{~nm})$ have been prepared [*22] by Peng et al. from the elements under hydrothermal conditions $\left(T=180{ }^{\circ} \mathrm{C}, t=24 \mathrm{~h}\right)$. This is an important reaction since water is the ideal solvent from most viewpoints. Were means to be found to reduce the particle size to the sub-10 nm range, this procedure has great potential for scale up. The cubic zinc blende structures were obtained from these reactions. At temperatures less than $180{ }^{\circ} \mathrm{C}$, the metal oxide or hydroxide and Se were obtained. This is perhaps to do with poor Se solubility below $180^{\circ} \mathrm{C}$.

Qian and coworkers [23] have reported wurtzite $\mathrm{ZnSe}$ nanoparticles with sizes in the $18-\mathrm{nm}$ range starting from the elements in ethylenediamine $\left(T=120^{\circ} \mathrm{C}, t=6 \mathrm{~h}\right)$. This reaction yields a complex with the formula $\mathrm{ZnSe}(\mathrm{en})$ where en is ethylenediamine. They have characterized this complex by X-ray diffraction and infrared spectroscopy. The complex on further treatment with dil. $\mathrm{HCl}$ gave large lamellar wurtzite $\mathrm{ZnSe}$ particles. It is important to keep the $\mathrm{HCl}$ concentration low to avoid dissolving $\mathrm{ZnSe}$. The complex could also be decomposed by heating to $300{ }^{\circ} \mathrm{C}$ in an argon atmosphere to obtain spherical $18-\mathrm{nm} \mathrm{ZnSe}$ particles.

\subsection{Redox reactions and precipitations}

CdS nanoparticles with different sizes and morphologies have been reported by Qian and coworkers [24] starting from the metal nitrates or sulphates, using thiourea as the $\mathrm{S}$ source. The solvents tried were water, ethanol, butanol, ethylene glycol, tetrahydrofuran (THF) or ethylenediamine. The smallest particles $(6 \mathrm{~nm})$ were obtained using ethylene glycol as the solvent $\left(T=180{ }^{\circ} \mathrm{C}, t=12 \mathrm{~h}\right)$. In the amine solvents, rods were obtained, instead of spherical particles.

Our own contribution to the area is the preparation of thiol-capped 3-nm CdSe nanoparticles that are easily redissolved in non-polar solvents [*25]. We use toluene as the solvent. The reactants are cadmium stearate and Se powder. Following older work on the preparation of complex selenides [26], we have added tetralin (tetrahydronaphthalene) as a reducing agent. Tetralin is aromatized to naphthalene in the presence of $\mathrm{Se}$, producing $\mathrm{H}_{2} \mathrm{Se}$ in the process. This reacts with cadmium stearate to give CdSe. The process is inexpensive and relatively safe, and yields surprisingly monodisperse quantum dots (the particle size distributions have a width that is about $5 \%$ of the mean) with good luminescence properties. Fig. 4 displays the TEM image of dodecanethiol-capped 3-nm CdSe 


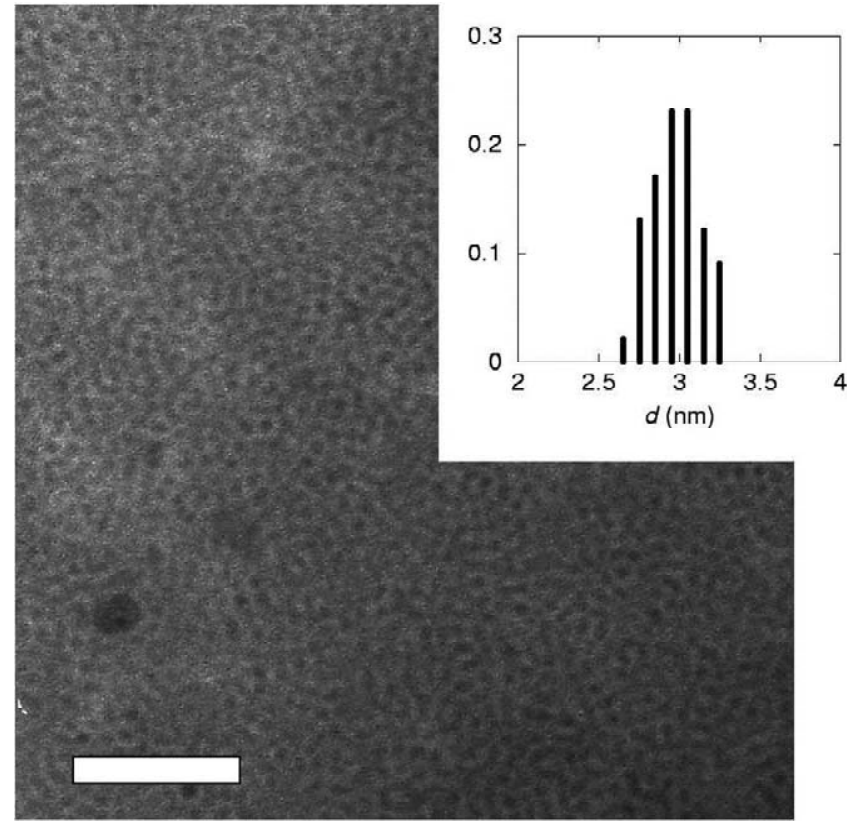

Fig. 4. TEM image of 3-nm dodecanethiol-capped CdSe nanoparticles prepared by the solvothermal reaction of cadmium stearate in toluene. The bar is $50 \mathrm{~nm}$. Reproduced with permission from The Royal Society of Chemistry [*25].

nanoparticles prepared solvothermally in toluene as described. To the best of our knowledge, this is the only report so far of a solvothermal route to surfactant-capped semiconductor chalcogenide nanoparticles.

$\mathrm{Cu}_{2-x}$ Se particles $(18 \mathrm{~nm})$ were obtained by Qian and coworkers [27] starting from CuI, Se, and ethylenediamine, with $T=90^{\circ} \mathrm{C}, t=4 \mathrm{~h}$. The particles are spherical and quite monodisperse; 6-nm $\mathrm{Co}_{9} \mathrm{~S}_{8}$ particles were prepared by Qian and coworkers [28] starting from the acetate $\mathrm{Co}\left(\mathrm{CH}_{3} \mathrm{COO}\right)_{2}$, hydrazine and thiourea in water, $T=170{ }^{\circ} \mathrm{C}, t=12 \mathrm{~h}$. Hydrazine plays an essential role here as a reducing agent, and in its absence, $\mathrm{CoS}$ was formed. A slight excess of Co was required to obtain near-stoichiometric materials. Particle sizes were estimated from X-ray diffraction line-broadening. At temperatures less than $160{ }^{\circ} \mathrm{C}$, the product was contaminated with $\mathrm{CoS}$.

SnSe particles $(45 \mathrm{~nm})$ could be obtained [29] starting from $\mathrm{SnCl}_{2}$, Se and $\mathrm{Na}$ as a reducing agent in ethylenediamine with $T=130{ }^{\circ} \mathrm{C}, t=5 \mathrm{~h}$. A slight excess of $\mathrm{Na}$ was required. The particles were spherical and quite monodisperse. Higher temperatures and longer reaction times lead to agglomeration and larger particles. It has been suggested that $\mathrm{Sn}^{2+}$ is chelated by ethylenediamine. In benzene, toluene or tetrahydrofuran, the reaction is incomplete; $25-\mathrm{nm} \mathrm{Bi}_{2} \mathrm{Se}_{3}$ particles [30] could similarly be made starting from $\mathrm{BiCl}_{3}$ and $\mathrm{Se}$ but using $\mathrm{NaI}$ as the reducing agent in ethylenediamine. The conditions were $T=130{ }^{\circ} \mathrm{C}, t=4 \mathrm{~h}$.

$\mathrm{In}_{2} \mathrm{~S}_{3}$ nanoparticles have been reported by Xiong and coworkers [31] starting from $\mathrm{InCl}_{3} \cdot 4 \mathrm{H}_{2} \mathrm{O}, \mathrm{Na}_{2} \mathrm{~S}_{2} \mathrm{O}_{3} \cdot 5 \mathrm{H}_{2} \mathrm{O}$ and ethanol. The conditions were $T=180{ }^{\circ} \mathrm{C}, t=24 \mathrm{~h}$. The reaction was also carried out in the presence of the surfactant CTAB (cetyl trimethylammonium bromide). The concentrations of the starting materials were found to influence the size and morphology of the particles. At low concentrations, 15-nm nanoparticles were obtained. When the concentration was increased, nanowhiskers and nanorods were obtained. CTAB reduced the particle size and led to narrower particle size distributions. The solvent itself undergoes oxidation leading to the reduction of $\mathrm{In}^{3+}$. The proposed reaction is

$$
\begin{aligned}
& 2 \mathrm{In}^{3+}+3 \mathrm{CH}_{3} \mathrm{CH}_{2} \mathrm{OH} \rightarrow 2 \mathrm{In}+3 \mathrm{CH}_{3} \mathrm{CHO}+6 \mathrm{H}^{+} \\
& \mathrm{S}_{2} \mathrm{O}_{3}^{2-}+2 \mathrm{H}^{+} \rightarrow \mathrm{S}+\mathrm{SO}_{2}+\mathrm{H}_{2} \mathrm{O} \\
& 2 \mathrm{In}+3 \mathrm{~S} \rightarrow \mathrm{In}_{2} \mathrm{~S}_{3}
\end{aligned}
$$

Qian and coworkers [32] have prepared $\mathrm{MSe}_{2}$ particles with $\mathrm{M}=\mathrm{Ni}$, $\mathrm{Co}$ and $\mathrm{Fe}$ from the reaction of $\mathrm{MCl}_{2}$ with a mixture of hydrazine and $\mathrm{Se}$ in alkaline conditions, solvothermally, using as solvents $\mathrm{H}_{2} \mathrm{O}, N, N$-dimethylformamide (DMF), pyridine, acetylacetone or ethylenediamine. Typical conditions involve $T=80-200{ }^{\circ} \mathrm{C}, t=12-48 \mathrm{~h}$. Control over particle size and shape could be achieved through changing the solvent, temperature and reaction time. For example, using DMF, spherical particles could be prepared. With pyridine at low temperatures, filaments were obtained. Hydrazine is necessary in order to reduce the chalcogen to the ion under alkaline conditions. Neither $\mathrm{CoSe}_{2}$ nor $\mathrm{FeSe}_{2}$ crystallize in the cubic pyrites phase but instead form orthorhombic compounds. $\mathrm{NiSe}_{2}$ however crystallizes in the usual cubic phase. The reactions are incomplete in water and acetylacetone, perhaps due to the lower solubility of $\mathrm{Se}$ in these solvents. In ethylenediamine, a complex is obtained instead of the chalcogenide.

Chen and Fan [*33] have prepared $\mathrm{MS}_{2}$ and $\mathrm{MSe}_{2}$ particles $(\mathrm{M}=\mathrm{Fe}, \mathrm{Co}, \mathrm{Ni}, \mathrm{Mo})$ with sizes ranging from 4 to $200 \mathrm{~nm}$ under hydrothermal conditions. They start with $\mathrm{MCl}_{2}$ (when $\mathrm{M}=\mathrm{Ni}$, Co or $\mathrm{Fe}$ ) and sodium thiosulphate $\mathrm{Na}_{2} \mathrm{~S}_{2} \mathrm{O}_{3}$ or sodium selenosulphate $\mathrm{Na}_{2} \mathrm{SSeO}_{3}$. The hydrothermal conditions are $T=140-150{ }^{\circ} \mathrm{C}, t=12 \mathrm{~h}$. Sodium selenosulphate is easily prepared by boiling an aqueous solution of sodium sulphite $\mathrm{Na}_{2} \mathrm{SO}_{3}$ with Se powder for 10 h. All the dichalcogenides of $\mathrm{Fe}, \mathrm{Co}$ and $\mathrm{Ni}$ were cubic. The $\mathrm{pH}$ of the starting solution was found to influence the reaction. For $\mathrm{pH}>7$ in the $\mathrm{NiS}_{2}$ preparation, $\mathrm{Ni}(\mathrm{OH})_{2}$ was the product. When the $\mathrm{pH}<3, \mathrm{NiS}$ and $\mathrm{Ni}_{3} \mathrm{~S}_{4}$ were the products. For the preparation of $\mathrm{MoS}_{2}$ and $\mathrm{MoSe}_{2}$, the starting materials were $\mathrm{Na}_{2} \mathrm{MoO}_{4}$, hydrazine (as a reducing agent) and $\mathrm{Na}_{2} \mathrm{~S}_{2} \mathrm{O}_{3} / \mathrm{Na}_{2} \mathrm{SSeO}_{3}$. The hydrothermal conditions were $T=135^{\circ} \mathrm{C}, t=12 \mathrm{~h}$. Reported sizes were from X-ray Scherrer broadening as well as from transmission electron microscopy and these were found to be consistent. The important reaction suggested for $\mathrm{ME}_{2}$ 
formation when $\mathrm{M}$ is $\mathrm{Fe}, \mathrm{Co}, \mathrm{Ni}$ is between the thiosulphate or selenosulphate ion and water according to:

$\mathrm{ESO}_{3}^{2-}+\mathrm{H}_{2} \mathrm{O} \rightarrow \mathrm{SO}_{4}^{2-}+2 \mathrm{H}^{+}+\mathrm{E}^{2-}$

where $\mathrm{E}$ is $\mathrm{S}$ or $\mathrm{Se}$. The $\mathrm{E}^{2-}$ ion precipitates the metal chalcogenide. The authors provide as evidence, the detection of $\mathrm{SO}_{4}^{2-}$ and $\mathrm{H}^{+}$in the reaction products. In the $\mathrm{MoS}_{2}$ case, even though sodium thiosulphate is a good reducing agent, hydrazine was needed for the reduction. $\mathrm{MoS}_{2}$ was formed in this reaction when the $\mathrm{pH}$ range was kept between 7 and 14. When the $\mathrm{pH}$ was less than 5, molybdenum bronzes were formed.

Qian and coworkers [34] report the solvothermal preparation of the important compound semiconductor $\mathrm{CuInSe}{ }_{2}$. They obtain $15-\mathrm{nm}$ particles starting from $\mathrm{CuCl}_{2}, \mathrm{InCl}_{3}$ and Se. The solvent was either ethylenediamine or diethylamine, with $T=180^{\circ} \mathrm{C}, 15 \mathrm{~h}$ when the solvent was ethylenediamine, and $36 \mathrm{~h}$ in the case of diethylamine. In ethylenediamine, whiskers were obtained. Spherical particles were obtained in diethylamine. The phase was chalcopyrite. The proposed reaction involves:

$2 \mathrm{InCl}_{3}+3 \mathrm{Se}^{2-} \rightarrow \mathrm{In}_{2} \mathrm{Se}_{3}+6 \mathrm{Cl}^{-}$

$\mathrm{In}_{2} \mathrm{Se}_{3}+\mathrm{Se}^{2-} \rightarrow 2\left(\mathrm{InSe}_{2}\right)^{-}$

$\mathrm{Cu}(\mathrm{en})_{2}+\mathrm{InSe}_{2}^{-} \rightarrow \mathrm{CuInSe}_{2}+2(\mathrm{en})$

CuInSe $_{2-x} \mathrm{~S}_{x}$ [35] has been prepared by Qian and coworkers using $\mathrm{InCl}_{3}, \mathrm{CuCl}_{2}, \mathrm{~S}$ and $\mathrm{Se}$ with ethylenediamine as the solvent $\left(T=180{ }^{\circ} \mathrm{C}, t=15 \mathrm{~h}\right)$. Diethylamine can also be used but longer times are required $(t=48 \mathrm{~h})$. The average particle size was $15 \mathrm{~nm}$.

$\mathrm{AgGaS}_{2}(5-7 \mathrm{~nm})$ and 9-12 $\mathrm{nm} \mathrm{AgInS}$ nanoparticles have been prepared [36] in a reaction involving $\mathrm{AgCl}$, the metal ( $\mathrm{Ga}$ or $\mathrm{In})$ and $\mathrm{S}$ in ethylenediamine $(T=180$ $\left.230{ }^{\circ} \mathrm{C}, t=10 \mathrm{~h}\right)$. Here, the solvent plays a dual role of dissolving $\mathrm{S}$ as well as complexing $\mathrm{Ag}^{+}$. The particles were spherical but agglomerated. The reaction cannot be carried out in pyridine or benzene. The suggested mechanism is:

$3 \mathrm{AgCl}+6 \mathrm{~S}+4 \mathrm{M} \rightarrow \mathrm{AgMS}_{2}+\mathrm{MCl}_{3}$

$\mathrm{CuMS}_{2}(\mathrm{M}=\mathrm{In}$ and $\mathrm{Ga})$ nanoparticles with sizes of the order of $10 \mathrm{~nm}(\mathrm{M}=\mathrm{In})$ and of the order of $35 \mathrm{~nm}$ $(\mathrm{M}=\mathrm{Ga})$ have been similarly prepared by the reaction of $\mathrm{CuCl}, \mathrm{M}$ and excess $\mathrm{S}$ in water [37] at $T=200^{\circ} \mathrm{C}$ and $t=12 \mathrm{~h}$. When the solvent was pyridine instead of water, larger particles were obtained. When ethylenediamine was used as the solvent, the particle shapes were irregular. The proposed mechanism is that $\mathrm{S}$ disproportionates to $\mathrm{S}^{2-}$ and an unspecified oxidized species with $\mathrm{S}$. The latter oxidizes the metal and the sulphide is precipitated. The reaction is like the one for the Ag compounds presented earlier:

$3 \mathrm{CuCl}+6 \mathrm{~S}+4 \mathrm{M} \rightarrow \mathrm{CuMS}_{2}+\mathrm{MCl}_{3}$
The products $\mathrm{AgGaS}_{2}$ and $\mathrm{AgInS}_{2}$ are both tetragonal chalcopyrites. In these reactions, the $\mathrm{M}$ ( $\mathrm{Ga}$ or In) melts and the reaction takes place through a liquid-solution diffusion process.

Using a combination of microemulsions and solvothermal techniques, Gan et al. [38] have prepared 12-nm Mn-doped $\mathrm{ZnS}$ nanoparticles. The microemulsions comprised petroleum ether as the oil, NP5 or NP9 surfactants, [these are poly(oxoethylene) 5 nonylphenolether, or poly(oxoethylene) ${ }_{9}$ nonylphenolether] and water. To one part of the emulsion, $\mathrm{Na}_{2} \mathrm{~S}$ was added and to the other, $\mathrm{MCl}_{2}$ added $(\mathrm{M}=\mathrm{Zn}$ and $\mathrm{Mn})$. These were mixed and treated solvothermally $\left(T=120^{\circ} \mathrm{C}, t=15 \mathrm{~h}\right)$. Mn content was $0.8 \mathrm{~mol} \%$ in the product. The particles were spherical but with a wide size distribution. Photoluminescence intensities of the samples were enhanced by a factor of 60 compared to the sample prepared by a conventional aqueous reaction at room temperature. This is attributed to the surface passivation of the Mn-doped $\mathrm{ZnS}$ nanocrystals and the formation of the cubic zinc blende structure.

\section{New developments in solvothermal preparations}

We mention here two relatively new techniques in solvothermal/hydrothermal chemistry that have, amongst other things, been employed for the preparation of oxide nanoparticles. We believe these to be important for possible scale-up of solvothermal routes to nanoparticles. The two techniques are: (i) microwave-solvothermal reactions and (ii) flow-solvothermal reactions.

Microwave-hydrothermal techniques employ polymeric bombs/autoclaves that are transparent to microwaves but whose aqueous contents couple and rapidly heat up to (provided the system is controlled) a temperature that is in turn governed by the pressure. Systems are commercially available for so-called microwave-hydrothermal digestion of analytes for analytical chemistry. These have been put to use by Komarneni and coworkers [**39] to prepare a number of different oxide nanoparticles. For example, they have prepared 5-20 nm $\mathrm{MnFe}_{2} \mathrm{O}_{4}, \mathrm{CoFe}_{2} \mathrm{O}_{4}, \mathrm{NiFe}_{2} \mathrm{O}_{4}$ and $\mathrm{ZnFe}_{2} \mathrm{O}_{4}$ ferrite particles. In a typical procedure, metal nitrates are treated with $\mathrm{NH}_{3}$ till a specific $\mathrm{pH}$ is reached. These are then subjected to digestion in the microwave hydrothermal assembly ( $\left.T=164-194{ }^{\circ} \mathrm{C}, t \sim 4 \mathrm{~min}\right)$. The remarkably small reaction times are worthy of note. In addition, as in any microwave heating process, the energy is not wasted since it is dumped to the solvent, not the bomb.

In flow-hydrothermal techniques, a preheated solvent is mixed with reactants just before introducing the mixture into a heated chamber whose pressure is controlled using a back-pressure regulator. The individual components can be constructed with Swagelok $^{\text {TM }}$ fittings. An essential feature is the pumping of the reactants using high-pressure pumps of the kind employed in high-performance liquid chroma- 


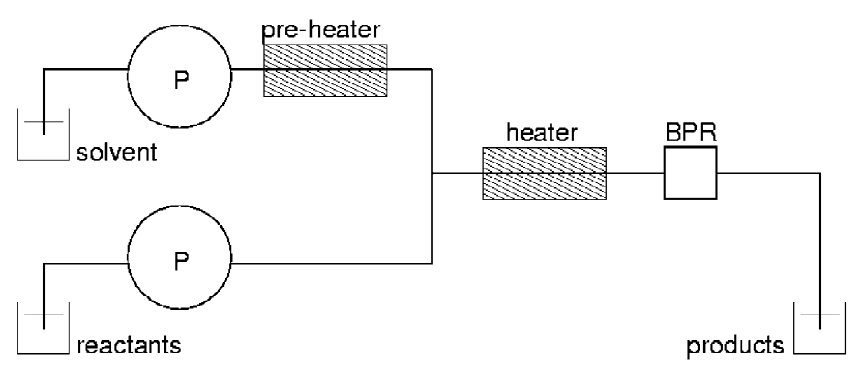

Fig. 5. Scheme of the flow-hydrothermal system used in Ref. [**40] for the preparation of oxide nanoparticles in a continuous process. The pumps $\mathrm{P}$, mix the preheated solvent and reactants and these are introduced into a chamber that is heated to the desired temperature. The system pressure is controlled by the back-pressure regulator (BPR). Adapted from Ref. [**40] with permission from the Royal Society of Chemistry.

tography (HPLC). Cabañas et al. [**40] have described the preparation of nanoparticulate $\mathrm{CeO}_{2}-\mathrm{ZrO}_{2}$ solid solutions using a system such as the one described. Mixed ceric ammonium nitrate and zirconium acetate solutions were added to preheated water at $400{ }^{\circ} \mathrm{C}$. The mixing point temperature then dropped to $300{ }^{\circ} \mathrm{C}$ at the flow rates used. A residence time of $9 \mathrm{~s}$ at a (regulated) pressure of $25 \mathrm{MPa}$ was sufficient to yield the product, which comprised nanoparticles with sizes as small as $4 \mathrm{~nm}$. Fig. 5 displays a schematic of the flow-solvothermal system used by these authors.

A criterion that helps in the preparation of monodisperse nanoparticles is the requirement that nucleation of the particles take place rapidly, and this is followed by a well-separated growth phase. During the growth phase, there should be no new nuclei formed. The reason is that if nuclei keep forming during the growth stage, the initially formed nuclei will grow into large nanoparticles while the nuclei formed at later stages will not grow very much. Both the new techniques listed here show great promise, not only for scale-up, but also for monodisperse nanoparticles, given that the microwave solvothermal technique involves rapid heating and that the flow-solvothermal technique involves short contact times.

\section{Acknowledgements}

We thank the Department of Science and Technology for their support of this work, and Dr M. Giridhar for discussions.

\section{References}

Papers of particular interest, published within the annual period of review, have been highlighted as:

* of special interest;

** of outstanding interest.
[1] Murray CB, Norris DJ, Bawendi MG. Synthesis and characterization of nearly monodisperse $\mathrm{CdE}(\mathrm{E}=\mathrm{S}$, Se, Te) semiconductor nanocrystallites. J Am Chem Soc 1993;115:8706-15.

[2] Trentler TJ, Denler TE, Bertone JF, Agrawal A, Colvin VL. Synthesis of $\mathrm{TiO}_{2}$ nanocrystals by nonhydrolytic solution-based reactions. J Am Chem Soc 1999;121:1613-4.

[3] Green M, O'Brien P. A simple one phase preparation of organically capped gold nanocrystals. J Chem Soc Chem Commun 2000:18384.

[4] Rockenberger J, Scher EC, Alivisatos AP. A new non-hydrolytic single-precursor approach to surfactant-capped nanocrystals of transition metal oxides. J Am Chem Soc 1999;121:11595-6.

[5] Klinowski J, Barrie PJ, editors, Recent advances in zeolite science, Amsterdam: Elsevier, 1990.

[6] Yu SH. Hydrothermal/solvothermal processing of advanced ceramic materials. J Ceram Soc Jpn 2001;109:S65-75.

[7] Smith JM, van Ness HC, Abbott MM. Introduction to chemical engineering thermodynamics, 6th edition. Singapore: McGraw-Hill, 2001.

[8] Reid RC, Prausnitz JM, Poling BE. The properties of liquids and gases, 4th edition. Singapore: McGraw-Hill, 1986.

[*9] Inoue M, Kimura M, Inui T. Transparent colloidal solution of $2 \mathrm{~nm}$ ceria particles. J Chem Soc Chem Commun 1999:957-58.

[10] Li Y, Duan X, Liao H, Qian Y. Self-regulation synthesis of nanocrystalline $\mathrm{ZnGa}_{2} \mathrm{O}_{4}$ by hydrothermal reaction. Chem Mater 1998;10:17-8.

[**11] Chemseddine A, Moritz T. Nanostructuring titania: Control over nanocrystal structure, size, shape, and organization. Eur J Inorg Chem 1999:235-45.

[12] Yanqing Z, Erwei S, Zhizhan C, Wenjun L, Xingfang H. Influence of solution concentration on the hydrothermal preparation of titania crystallites. J Mater Chem 2001;11:1547-51.

[13] Yin H, Wada Y, Kitamura T, Sumida T, Hasegawa Y, Yanagida S. Novel synthesis of phase-pure nano-particulate anatase and rutile $\mathrm{TiO}_{2}$ using $\mathrm{TiCl}_{4}$ aqueous solutions. J Mater Chem 2002;12:37883.

[14] Zhao J, Fan W, Wu D, Sun Y. Stable nanocrystalline zirconia sols prepared by a novel method; alcohol thermal synthesis. J Mater Res 2000;15:402-6.

[15] Hirano M. Hydrothermal synthesis and characterization of $\mathrm{ZnGa}_{2} \mathrm{O}_{4}$ spinel fine particles. J Mater Chem 2000;10:469-72.

[16] Wu M, Long J, Huang A, Luo Y, Feng S, Xu R. Microemulsionmediated hydrothermal synthesis and characterization of nanosized rutile and anatase particles. Langmuir 1999;15:8822-5.

[*17] Thimmaiah S, Rajamathi M, Singh N, Bera P, Meldrum FC, Chandrasekhar N, Seshadri R. A solvothermal route to capped nanoparticles of $\gamma-\mathrm{Fe}_{2} \mathrm{O}_{3}$ and $\mathrm{CoFe}_{2} \mathrm{O}_{4}$. J Mater Chem 2001;11:3215-21.

[18] Elerman Y, Atakol O, Svoboda I, Geselle M. Bis(cupferronato)copper(II), $\left[\mathrm{Cu}\left(\mathrm{C}_{6} \mathrm{H}_{5} \mathrm{~N}_{2} \mathrm{O}_{2}\right)_{2}\right]$. Acta Crystallogr 1995;C51:1520-2.

[19] Li YD, Duan XF, Qian YT, Yang L, Ji MR, Li CW. Solvothermal co-reduction route to the nanocrystalline III-V semiconductor InAs. J Am Chem Soc 1997;119:7869-70.

[**20] Qian Y. Solvothermal synthesis of nanocrystalline III-V semiconductors. Adv Mater 1999;11:1101-2.

[21] Li Y, Ding Y, Qian Y, Zhang Y, Yang L. A solvothermal elemental reaction to produce nanocrystalline $\mathrm{ZnSe}$. Inorg Chem 1998;37:2844-5.

[*22] Peng Q, Dong Y, Deng Z, Sun X, Li Y. Low-temperature elementaldirect-reaction route to II-VI semiconductor nanocrystalline $\mathrm{ZnSe}$ and CdSe. Inorg Chem 2001;40:3840-1.

[23] Zhan JH, Yang XG, Zhang WX, Wang DW, Xie Y, Qian YT. A solvothermal route to wurtzite $\mathrm{ZnSe}$ nanoparticles. J Mater Res 2000;15:629-32.

[24] Yu SH, Yang J, Han ZH, Zhou Y, Yang RY, Qian YT, Zhang YH. Controllable synthesis of nanocrystalline CdS with different morphologies and particle sizes by a novel solvothermal process. J Mater Chem 1999;9:1283-7. 
[*25] Gautam UK, Rajamathi M, Meldrum F, Morgan P, Seshadri R. A solvothermal route to capped CdSe nanoparticles. J Chem Soc Chem Commun 2001:629-30.

[26] Mitchell PWD, Morgan PED. Direct precipitation method for complex crystalline chalcogenides. J Am Ceram Soc 1974;57:278.

[27] Wang W, Yan P, Liu F, Xie Y, Geng Y, Qian Y. Preparation and characterization of nanocrystalline $\mathrm{Cu}_{2-x}$ Se by a novel solvothermal pathway. J Mater Chem 1998;8:2321-2.

[28] Zhan JH, Yang XG, Xie Y, Wang DW, Qian YT, Liu XM. Hydrazine-controlled hydrothermal synthesis of $\mathrm{Co}_{9} \mathrm{~S}_{8}$ from a homogeneous solution. J Mater Res 1999;14:4418-20.

[29] Wang W, Geng Y, Qian Y, Wang C, Liu X. A convenient, low temperature route to nanocrystalline SnSe. Mater Res Bull 1999;34:403-6.

[30] Wang W, Geng Y, Qian Y, Xie Y, Liu X. Synthesis and characterization of nanocrystalline $\mathrm{Bi}_{2} \mathrm{Se}_{3}$ by solvothermal method. Mater Res Bull 1999;34:131-4.

[31] Xiong Y, Xie Y, Du G, Tian X. A solvent-reduction and surfacemodification technique to morphology control of tetragonal $\operatorname{In}_{2} \mathrm{~S}_{3}$ nanocrystals. J Mater Chem 2002;12:98-102.

[32] Yang J, Cheng GH, Zeng JH, Yu SH, Liu XM, Qian YT. Shapecontrol and characterization of transition metal diselenides $\mathrm{MSe}_{2}$ $(\mathrm{M}=\mathrm{Ni}, \mathrm{Co}, \mathrm{Fe})$ prepared by a solvothermal-reduction process. Chem Mater 2001;13:848-53.

[*33] Chen X, Fan R. Low-temperature hydrothermal synthesis of transition metal dichalcogenides. Chem Mater 2001;13:802-5.
[34] Li B, Xie Y, Huang H, Qian Y. Synthesis by a solvothermal route and characterization of $\mathrm{CuInSe}_{2}$ nanowhiskers and nanoparticles. Adv Mater 1999;11:1456-9.

[35] Xiao J, Xie Y, Xiong Y, Tang R, Qian Y. A mild solvothermal route to chalcopyrite quaternary semiconductor $\mathrm{CuIn}\left(\mathrm{Se}_{\mathrm{x}} \mathrm{S}_{1-\mathrm{x}}\right)_{2}$ nanocrystallites. J Mater Chem 2001;11:1417-20.

[36] Hu J, Lu Q, Tang K, Qian Y, Zhou G, Liu X. Solvothermal reaction route to nanocrystalline semiconductors $\operatorname{AgMS}_{2}(\mathrm{M}=\mathrm{Ga}$, In). J Chem Soc Chem Commun 1999:1093-94.

[37] Lu Q, Hu J, Tang K, Qian Y, Zhou G, Liu X. Synthesis of nanocrystalline $\mathrm{CuMS}_{2}(\mathrm{M}=\mathrm{In}, \mathrm{Ga})$ through a solvothermal process. Inorg Chem 2000;39:1606-7.

[38] Gan LM, Liu B, Chew CH, Xu SJ, Chua SJ, Loy GL, Xu GQ. Enhanced photoluminescence and characterization of Mn-doped $\mathrm{ZnS}$ nanocrystallites synthesized in microemulsion. Langmuir 1997;13:6427-31.

[**39] Komarneni S, D'Arigo MC, Leonelli C, Pellacani GC, Katsuki H. Microwave-hydrothermal synthesis of nanophase ferrites. J Am Ceram Soc 1998;81:3041-3.

[**40] Cabañas A, Darr JA, Lester E, Poliakoff M. A continuous and clean one-step synthesis of nano-particulate $\mathrm{Ce}_{1-\mathrm{x}} \mathrm{Zr}_{\mathrm{x}} \mathrm{O}_{2}$ solid solutions in near-critical water. J Chem Soc Chem Commun 2000;901-2; Cabañas A, Darr JA, Lester E, Poliakoff M. Continuous hydrothermal synthesis of inorganic materials in a near-critical water flow reactor; the one-step synthesis of nanoparticulate $\mathrm{Ce}_{1-\mathrm{x}} \mathrm{Zr}_{\mathrm{x}} \mathrm{O}_{2}(\mathrm{x}=0$, 1) solid solutions. J Mater Chem 2001;11:561-8. 